\title{
A study on the protective mechanism of mTOR inhibitor Everolimus on brain injury after epilepsy
}

\section{Xiang-yi Huang}

The Second Hospital, University of South China

Qing-peng Hu ( $\nabla$ penghu2025@163.com )

The Second Hospital, University of South China https://orcid.org/0000-0001-9541-393X

\section{Ya-yu Zheng}

The Second Hospital, University of South China

\section{Rong-rong Hu}

The Second Hospital, University of South China

\section{Research article}

Keywords: Everolimus, epilepsy, PI3K/AKt, NF-kB /IL-6, microglia

Posted Date: June 4th, 2020

DOI: https://doi.org/10.21203/rs.3.rs-23882/v1

License: (c) (i) This work is licensed under a Creative Commons Attribution 4.0 International License. Read Full License 


\title{
A study on the protective mechanism of mTOR inhibitor Everolimus
}

\section{on brain injury after epilepsy}

Xiang-yi Huang 1, Qing-peng $\mathrm{Hu}$ *, Ya-yu Zheng 2, Rong-rong Hu2

1 Department of Function Examination, The Second Hospital, University of South

China, Hengyang, Hunan, 421001, China. E-mail: xiangdy8699@126.com

Corresponding Author : * Department of Pediatrics, The Second Hospital, University

of South China, Hengyang, Hunan, 421001, China. E-mail: penghu2025@163.com

${ }_{2}$ Department of Pediatrics, The Second Hospital, University of South China,

Hengyang, Hunan, 421001, China.

\begin{abstract}
:
Background: Epilepsy is a common acute and severe disease in infants and children. Recurrent seizures or status epilepticus can cause irreversible brain damage. While the PI3K/Akt/mTOR pathway regulates various physiological processes of neurons and glia, it may also lead to abnormal neuronal signal transduction under pathological conditions, including that of epilepsy. Everolimus (Eve) is an mammalian target of repamycin (mTOR) inhibitor that may affect neuronal excitability and have a therapeutic effect on epilepsy. Therefore, this study aimed to investigate the protective effect of Everolimus on post-epileptic brain injury and the regulation mechanism of the PI3K/Akt/mTOR and NF-kB/IL-6 signaling pathway. Intraperitoneal administration of kanic acid (KA) $15 \mathrm{mg} / \mathrm{kg}$ was used to induce epilepsy in the developing rat and Everolimus $(1,2,5 \mathrm{mg} / \mathrm{kg}$ ) was injected intraperitoneally 2 hours before KA injection. Cerebral cortex tissue was sampled at 24 hours post-epilepsy. Results: The protein and mRNA levels of PI3K、AKt、mTOR 、 NF-kB and IL-6 as well as microglia activation significantly increased after KA-induced epilepsy, however these effects were inhibited by Everolimus treatment. Furthermore, pretreatment with Everolimus decreased seizure scores and increased seizure latency. This study demonstrates that mTOR inhibitor Conclusions: Everolimus can decrease the PI3K/Akt/mTOR and NF-kB/IL-6 signaling pathway, reduce microglia activation, and attenuate seizure susceptibility and intensity, thus having a protective effect on post-epileptic brain damage.
\end{abstract}

Keywords: Everolimus, epilepsy, PI3K/AKt, NF-kB /IL-6, microglia;

\section{Background}

Epilepsy is a brain dysfunction syndrome, caused by recurrent seizures due to abnormal discharge of brain neurons. The pathogeny of epilepsy is complex and diverse and may be attributed to genetic factors, intracranial infection, craniocerebral injury, cerebrovascular disease and/or systemic diseases [1]. The first-line treatment of epilepsy is usually drug therapy, however these current therapeutics largely control disease symptoms rather than targeting the underlying disease processes [2]. It is therefore very important to explore the pathogenesis of epilepsy and find novel antiepileptic drugs. 
mTOR is a protein kinase that participates in the highly conserved PI3K/AKT signaling pathway, which regulates cell growth and survival, metabolism and autophagy, migration and motility [3]. The mTOR cascade plays a critical role in normal cortical development and remains functionally active. Studies have reported that PI3K/Akt /mTOR not only regulates various physiological processes of neurons and glia, but also participates in synaptic structure and plasticity, which may lead to abnormal neuronal signal transduction under pathological conditions [4]. Since $\mathrm{PI} 3 \mathrm{~K} / \mathrm{Akt} / \mathrm{mTOR}$ plays an important role in regulating various cell functions, we speculate that the PI3K/Akt/mTOR signaling pathway is likely involved in the pathological process of epilepsy.

Microglia are intrinsic immune effector cells and an important source of pro-inflammatory factors and oxidative stress in the central nervous system [5]. Involvement of microglia in epilepsy may occur through various mechanisms such as increasing gap junction coupling, inhibiting glutamate transporter function and damaging the blood-brain barrier [6]. Studies have shown that activated microglia can activate the mTOR signaling pathway, causing neuronal dendritic damage [7]. Furthermore, the activated mTOR signal can affect immune response and brain development, and may cause the process of subsequent epilepsy [8]. Given the postulated role of microglia in epileptic development and mTOR signaling activation, we explored therapeutic-induced changes in microglia activation in this study.

Everolimus is an mTOR inhibitor that can enhance the anti-inflammatory activity of regulatory $\mathrm{T}$ cells, reduce inflammatory cytokines and chemokines produced by macrophages and microglia, and reduce secondary injury after focal ischemia [9]. Studies have shown that in various hereditary and acquired epilepsy animal models, mTOR activation leads to nerve excitement and seizures. The inhibitory effect of Everolimus on mTOR reduces the intensity and frequency of seizures [10], which indicates that there is a close relationship between mTOR and epilepsy. Therefore, Everolimus is likely to affect neuronal excitability and have a therapeutic effect on epilepsy. In this experiment, by establishing a rat epilepsy model and intervening with mTOR inhibitor Everolimus, we observed changes in microglia activation, and the $\mathrm{PI} 3 \mathrm{~K} / \mathrm{Akt} / \mathrm{mTOR}$ and NF-kB/IL-6 signaling pathways to better understand the role and mechanism of Everolimus in post-epileptic brain injury.

\section{Methods}

\subsection{Animals}

Developing male Sprague-Dawley rats (weighing 60-80g, 3 weeks old) were obtained from the Experimental Animal Center, University of South China (Hengyang, Hunan, China). Animals were housed in conventional conditions on a $12 \mathrm{~h}$ light/dark cycle with free access to water and food. The temperature was maintained at $25{ }^{\circ} \mathrm{C}$ and the humidity at $50-60 \%$. The experimental protocols were approved by the Animal Care and Use Committee of University of South China and complied with the requirements of the National Health Center 


\subsection{Reagents}

KA and Everolimus were purchased from Sigma-Aldrich (St. Louis, MO, USA). BCA Protein Quantitative Kit was purchased from Biyuntian Company (Shanghai, China) and PVDF membrane were purchased from Millipore (Bedford, MA). PI3K、 Akt and mTOR mouse anti-rat antibodies were purchased from Cell Signaling Technology (Danvers, MA, USA), NF-kB、IL-6 and $\beta$-actin mouse anti-rat antibodies were purchased from Santa Cruz Biotechnology (CA, USA) and Anti-Iba1 antibody was purchased from Wako Pure Chemical Industries (Osaka, Japan). ECL chemiluminescence was purchased from Santa Cruz (Texas, USA). cDNA Reverse Transcription Kit and qRT-PCR Kit were purchased from Thermo Fisher Scientific (UK). Trizol kit was purchased from Invitrogen (Grand Island, NY, USA), and immunohistochemistry kit was purchased from Shanghai Yuanmu Biotechnology Company (Shanghai, China).

\subsection{Establish rat epilepsy model}

Male Sprague-Dawley rats were randomly divided into five groups: (1) control group; (2) KA group; (3) KA+1mg/kg Eve group (4) KA+2mg/kg Eve group (5) $\mathrm{KA}+5 \mathrm{mg} / \mathrm{kg}$ Eve group. A seizure model in developing rats was established by intraperitoneal injection of $15 \mathrm{mg} / \mathrm{kg}$ Kanic acid. The control group was only injected with saline. Behavioral seizures were graded on the Racine scale [11]: (stage 1) facial clonus; (stage 2) rhythmicity head nodding; (stage 3) forelimb clonus; (stage 4) seizures characterized by rearing or hind limb extension; (stage 5) seizures with rearing, jumping, and falling. A grade IV-V seizure indicates successful modeling. Eve $(1,2$ or $5 \mathrm{mg} / \mathrm{kg})$ was administered intraperitoneally 2 hours before KA induced-epilepsy. After behavioral assessments, the rats were sacrificed with an anesthetic ( $1 \%$ barbital sodium, $500 \mathrm{mg} / \mathrm{kg}$ ) 24 hours after seizure. The rats were then perfused transcardially with saline and the cerebral cortex tissues were immediately collected. The samples were stored at $-80^{\circ} \mathrm{C}$ for subsequent experiments.

\subsection{Immunohistochemistry to observe microglia activation}

The paraffin sections were baked in a $60^{\circ} \mathrm{C}$ oven for 2 hours, dewaxed and washed three times with PBS pH 7.4. The dewaxed and hydrated tissue sections were placed in boiling citrate buffer solution for antigen repair. After 10 minutes, the slices were removed from the buffer solution and rinsed 3 times with PBS. 1 drop of $3 \% \mathrm{H}_{2} \mathrm{O}_{2}$ was added to each slice and incubated at room temperature for 10 minutes to block the activity of endogenous peroxidase. After 3 PBS rinses, mouse anti-rat primary antibody Iba1 (1: 100) was added to each slice and incubated at room temperature for 2 hours, followed by 3 PBS rinses, the addition of rabbit anti-mouse secondary antibody and incubation at room temperature for 30 minutes. After 3 additional PBS rinses, sections were reacted with DAB solution for 5 minutes. Finally, sections were mounted onto gelatin-coated glass slides and air-dried. The activated microglia were observed with an optical microscope. Five high-power fields ( $\times 400$ times) with the same area were randomly selected for each slice, and the number of Ibal staining positive cells in each field was visually counted, and the average value was the 
number of activated microglia.

1.5 Western blot to detect the protein levels

Harvested cerebral cortex were washed in ice-cold PBS and lysed for 10 minutes using PMSF protease inhibitor and RIPA lysate. The lysates were collected and transferred to microcentrifuge tubes for centrifugation at $12,000 \mathrm{x}$ g for 30 minutes at $4^{\circ} \mathrm{C}$. The supernatant was collected and BCA protein assays measured the protein concentration in the lysate supernatant. 10\% separation gel and 3\% concentrated gel were prepared according to instructions and put into the electrophoresis tank. The sample was mixed with $5 \times$ Loading buffer at a volume of $4: 1$ and boiled at $98^{\circ} \mathrm{C}$ for 5 minutes; the total amount of protein remained the same when loading. Electrophoresis liquid was added to the electrophoresis tank, the protein moved from the concentrated gel to the separation gel at constant voltage. After electrophoresis, total protein $(30 \mu \mathrm{g})$ were separated electrophoretically by SDS-PAGE and subsequently transferred onto a polyvinylidene difluoride membrane. The membranes were soaked in 5\% skimmed milk as blocking buffer for 2 hours and then incubated with primary antibodies (mouse anti-rat): PI3K (1:2000), Akt (1:1000), mTOR (1:2000), NF-kB (1:1000) and IL-6 (1:3000) at $4^{\circ} \mathrm{C}$ overnight. After washing the membrane 3 times with PBS, the membranes were incubated with secondary antibody (rabbit anti-mouse 1:2000) at room temperature for 2 hours. ECL luminescent solutions A and B were mixed in equal volumes, and the PVDF membrane was immersed in the luminescent solution for 5 minutes. After three PBS rinses, the protein bands were scanned with the Image Quant TM LAS 4000 imaging system, and the scan results were analyzed with ImageJ software.

\subsection{Reverse transcription-quantitative polymerase chain reaction (qRT-PCR )}

Cerebral cortex tissue was lysed with Trizol lysate and chloroform, and RNA was extracted through separation, precipitation and drying. According to the instructions of Thermo Scientific cDNA Synthesis Kit, sample RNA, reverse transcriptase, upstream and downstream primers were mixed to synthesize template cDNA. According to the requirements of the qRT-PCR kit, cDNA, upstream and downstream primers were mixed to perform DNA amplification on the PCR machine. qRT-PCR primers are shown in Table 1. The qRT-PCR cycle amplification conditions are as follows: PI3K, denaturation: $95^{\circ} \mathrm{C}, 45 \mathrm{~s}$; annealing: $58^{\circ} \mathrm{C}, 45 \mathrm{~s}$; extension: $72^{\circ} \mathrm{C}, 1 \mathrm{~min}$; 30 cycles; Akt, denaturation: $95^{\circ} \mathrm{C}, 45 \mathrm{~s}$; annealing: $52^{\circ} \mathrm{C}, 1 \mathrm{~min}$; extension: $70^{\circ} \mathrm{C}, 1$ min; 30 cycles; mTOR, denaturation: $95^{\circ} \mathrm{C}, 45 \mathrm{~s}$; annealing: $56^{\circ} \mathrm{C}, 45 \mathrm{~s}$; extension: $72^{\circ} \mathrm{C}, 1 \mathrm{~min}$; 30 cycles; NF-kb, denaturation: $95^{\circ} \mathrm{C}, 45 \mathrm{~s}$; annealing: $55^{\circ} \mathrm{C}, 45 \mathrm{~s}$; extension: $70^{\circ} \mathrm{C}, 1 \mathrm{~min}$; 30 cycles; IL-6, denaturation: $95^{\circ} \mathrm{C}, 1 \mathrm{~min}$; annealing: $57^{\circ} \mathrm{C}$; extension: $72^{\circ} \mathrm{C}, 45 \mathrm{~s} ; 30$ cycles; GAPDH (Internal reference), denaturation: $95^{\circ} \mathrm{C}, 30 \mathrm{~s}$; annealing: $58^{\circ} \mathrm{C}, 30 \mathrm{~s}$; extension: $72^{\circ} \mathrm{C}, 30 \mathrm{~s} ; 28$ cycles. Cooling at $4^{\circ} \mathrm{C}$ after DNA amplification. 
Table 1 Nucleotide sequences of qRT-PCR primers

\begin{tabular}{lcc}
\hline Gene & Forward primer & Reverse primer \\
\hline PI3K & 5'-TAT TTGGACTTTGCGACAAGACT-3' & 5'-TCG AACGTACTGGTCTGGATAG-3' \\
Akt & 5'-AGCG ACGTGGCTATTGTGAAG-3' & 5'-GCCATC ATTCTTGAGGAGGAAGT-3' \\
mTOR & 5'-GCCAGGATGAGCGTGTGAT -3' & \\
GAPDH & 5'-GGAGCGAGATCCCTCCAAAAT-3' & 5'-TTGGGTCATTGGCCAGAAG-3' \\
NF-kb & 5'-GACCTGGAGCAAGCCATTAGC-3' & 5'-CGGACCGCATTCAAGTCATAGT-3' \\
IL-6 & 5'-GCTGGAGTCACAGAAGGAGTGGC-3' & 5'-GGCATAAC GCACTAGGTTTGCCG-3' \\
\hline
\end{tabular}

\subsection{Statistical analysis}

All data were analyzed using SPSS 20.0 statistical software. Measurement data were expressed as mean \pm standard deviation (Mean \pm SD). Means comparison between two groups were analyzed by t-test. Means comparison between multiple groups were analyzed by one-way analysis of variance (ANOVA) followed by Bonferroni post-hoc testing. $\mathrm{P}<0.05$ was considered statistically significant.

\section{Results}

2.1 Everolimus extends seizure latency and reduces seizure grade scores

In this experiment, KA $15 \mathrm{mg} / \mathrm{kg}$ induced developmental rat epilepsy, and different doses of Everolimus $(1,2,5 \mathrm{mg} / \mathrm{kg})$ were injected intraperitoneally 2 hours prior to KA injection. The seizure grade scores and seizure latency in different groups were as follows (Table 2): the seizure grade scores: Control group 0; KA group 3.85 \pm 0.93 ; $\mathrm{KA}+1 \mathrm{mg} / \mathrm{kg}$ Eve group $3.10 \pm 1.33 ; \mathrm{KA}+2 \mathrm{mg} / \mathrm{kg}$ Eve group $2.25 \pm 1.65 ; \mathrm{KA}+5 \mathrm{mg} / \mathrm{kg}$ Eve group 2.45 \pm 1.63 . The seizure latency: KA group 10.20 $\pm 3.31 \mathrm{~min}$; $\mathrm{KA}+1 \mathrm{mg} / \mathrm{kgEve}$ group $19.07 \pm 5.45 \mathrm{~min} ; \mathrm{KA}+2 \mathrm{mg} / \mathrm{kg}$ Eve group $27.14 \pm 11.19 \mathrm{~min}$; $\mathrm{KA}+5 \mathrm{mg} / \mathrm{kg}$ Eve group $22.97 \pm 8.29 \mathrm{~min}$.

The Everolimus treatment group exhibited significantly lower seizure scores and increased seizure latency when compared with the KA group (Figures 1 and .2). Further comparison of the seizure latency showed that the $2 \mathrm{mg} / \mathrm{kg}$ Eve group was significantly different from the $1 \mathrm{mg} / \mathrm{kg}$ Eve group $(\mathrm{P}<0.05)$. The assessment of both 
seizure latency and seizure score thereby indicates that Everolimus treatment can attenuate KA-induced epilepsy.

Table 2. Rat seizure score ( $\mathrm{n}=20$ per group)

\begin{tabular}{lccccccc}
\hline & No seizure & stage1 & stage2 & stage3 & stage4 & stage5 & mean score \\
\hline KA & 0 & 0 & 2 & 4 & 9 & 5 & $3.85 \pm 0.93$ \\
KA+1 mg/kg Eve & 1 & 1 & 4 & 6 & 5 & 3 & $3.10 \pm 1.33$ \\
KA+2mg/kg Eve & 4 & 3 & 4 & 4 & 3 & 2 & $2.25 \pm 1.65$ \\
KA+5mg/kg Eve & 3 & 4 & 2 & 5 & 4 & 2 & $2.45 \pm 1.63$ \\
Control & 20 & 0 & 0 & 0 & 0 & 0 & 0 \\
\hline
\end{tabular}

The number of rats in different seizures stage were counted and mean seizure score was analyzed by statistical method. Measurement data were expressed as mean \pm SD.

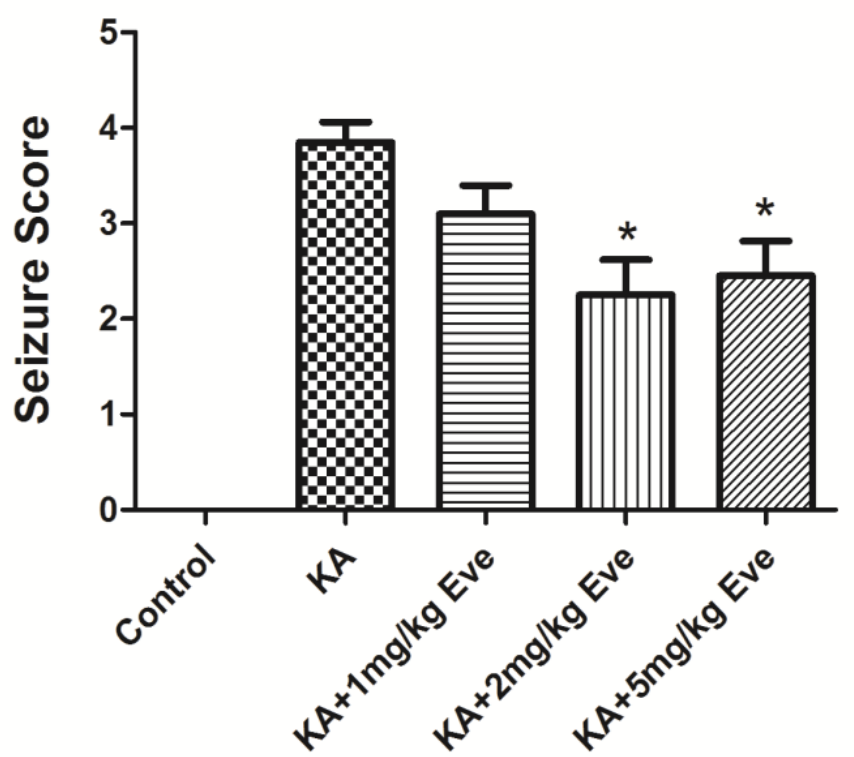

Fig. 1 Everolimus reduces seizure grade scores. KA $15 \mathrm{mg} / \mathrm{kg}$ induced developmental rat epilepsy, and different doses of Everolimus $(1,2,5 \mathrm{mg} / \mathrm{kg}$ ) were injected intraperitoneally 2 hours before KA injection. Seizure stage was assessed during 0.5-1 hours after KA injection. Measurement data were expressed as mean $\pm \mathrm{SD}(\mathrm{n}=20)$. $* \mathrm{P}<0.05$, compared with KA group. 


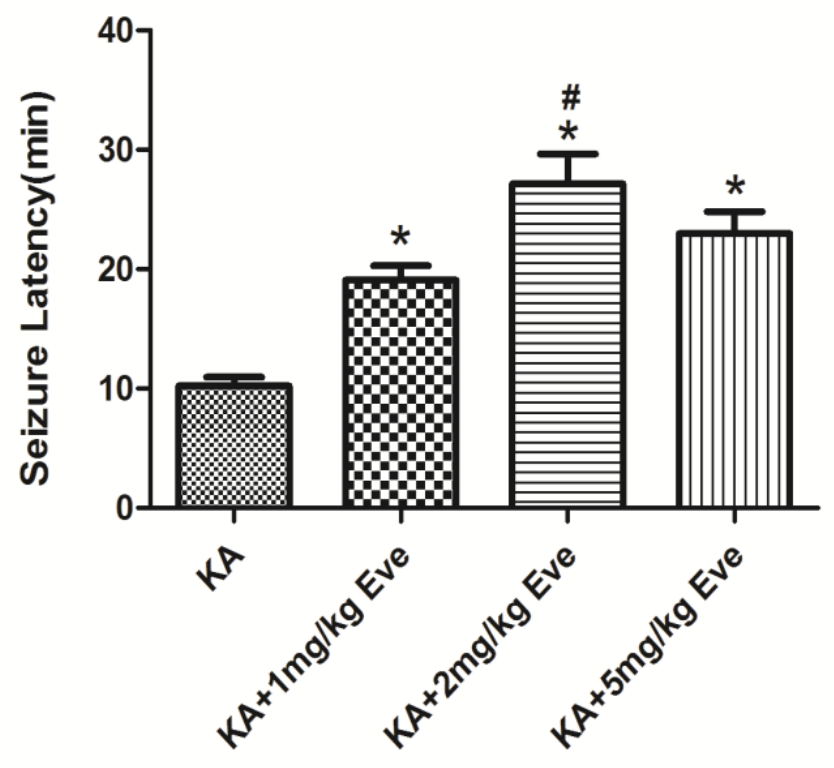

Fig. 2 Everolimus increases seizure latency. KA $15 \mathrm{mg} / \mathrm{kg}$ induced developmental rat epilepsy, and different doses of Everolimus (1, 2, $5 \mathrm{mg} / \mathrm{kg}$ ) were injected intraperitoneally 2 hours before KA injection. Seizure latency was assessed. Measurement data were expressed as mean $\pm \mathrm{SD}(\mathrm{n}=20)$. $* \mathrm{P}<0.05$, compared with KA group; $\# \mathrm{P}<0.05$, compared with $\mathrm{KA}+1 \mathrm{mg} / \mathrm{kg}$ Eve group.

2. 2 Everolimus reduces microglia activation

Immunohistochemistry was used to observe microglia activation in cerebral cortex 24 hours after epilepsy by detecting the expression of Iba1, a marker of activated microglia. (Figure 3).

In the Control group, the background was light blue, and the microglia were in a stationary state with a small cell body and long, thin radial branches (Figure 3A). In the KA group, the background was yellow-brown colour, and a large number of Iba1 positive cells were visible; the cell volume became larger, amoebic or round, and the cell protrusions became shorter or disappeared, suggesting the number of activated microglia had increased significantly after KA-induced epilepsy $(\mathrm{p}<0.05)$ (Figure 3B, 3F). Compared to the KA group, Everolimus treatment groups exhibited a lighter background color, reduced cell volume and decreased Ibal positive cells $(p<0.05)$ (Figure 3B-F). The treatment dose of $2 \mathrm{mg} / \mathrm{kg}$ Everolimus had the most significant observed effects (Figure 3F).

Immunohistochemical staining therefore suggests that Everolimus can reduce the activation of microglia after epilepsy and may have protective effects on brain damage. 

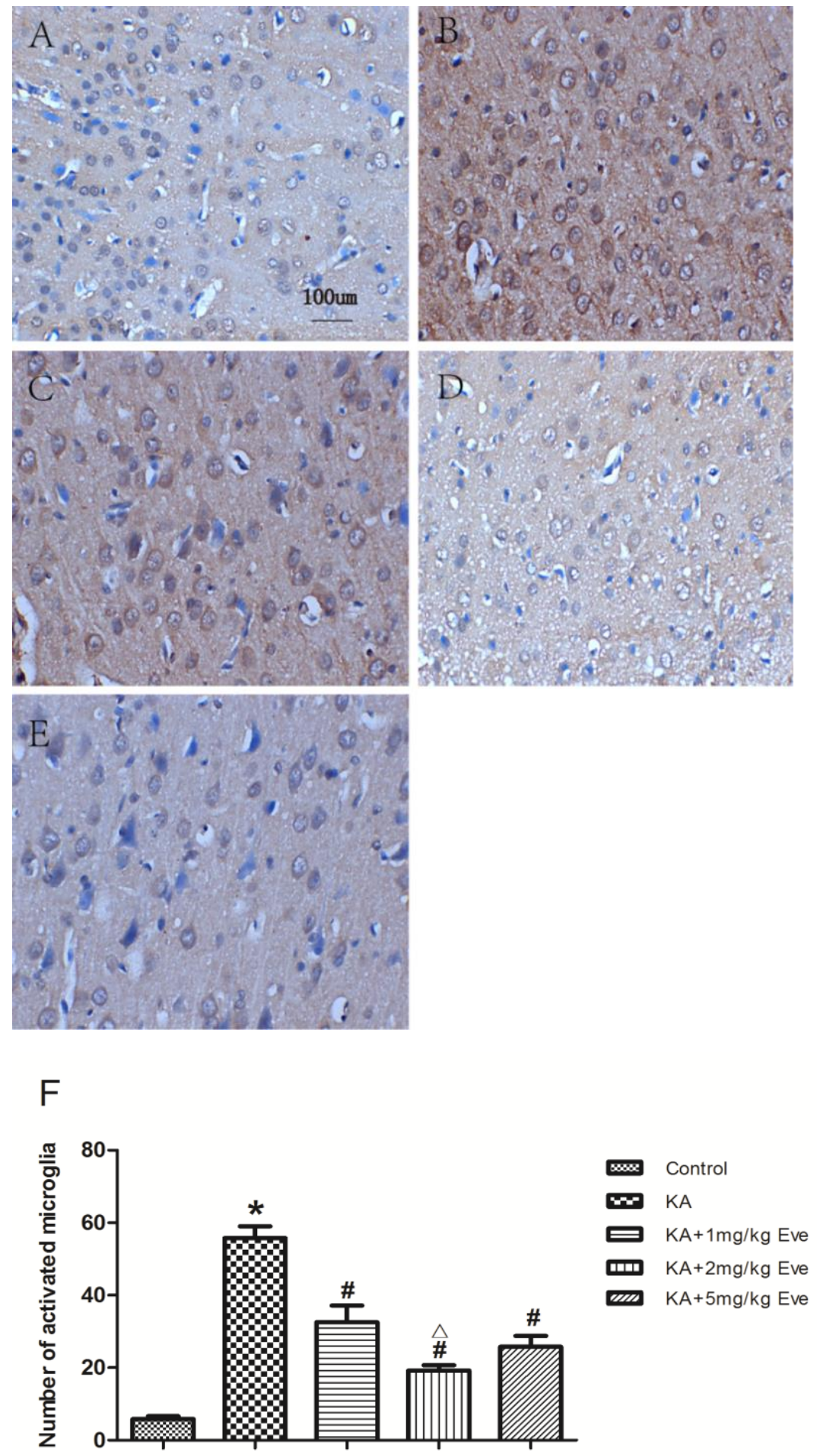

Fig. 3 Everolimus reduces microglia activation in the cerebral cortex. KA $15 \mathrm{mg} / \mathrm{kg}$ induced developmental rat epilepsy, and Everolimus $(1,2,5 \mathrm{mg} / \mathrm{kg}$ ) was injected intraperitoneally 2 hours before KA injection. Pathological sections of brain tissue were observed 24 hours after KA injection. A. Control group B. KA group C. KA+1mg/kg Eve group D. KA+2mg/kg Eve group E. KA $+5 \mathrm{mg} / \mathrm{kg}$ Eve group. F. Iba1 positive cells quantities for each group. Measurement data were expressed as mean \pm SD. Scale bar $=100 \mu \mathrm{m}$. $* \mathrm{P}<0.05$, KA group vs. control group; $\# \mathrm{P}<0.05$, Everolimus treated group $(1,2,5 \mathrm{mg} / \mathrm{kg})$ vs. KA group; $\triangle \mathrm{P}<0.05$, $\mathrm{KA}+2 \mathrm{mg} / \mathrm{kg}$ Eve group vs. KA+1 $\mathrm{mg} / \mathrm{kg}$ Eve. 
2.3 Everolimus reduces the expression of PI3K、Akt and mTOR

To explore the effect of Everolimus on the PI3K/Akt/mTOR signaling pathway, Western Blot and qRT-PCR were used to determine the protein and mRNA levels, respectively, of PI3K, Akt and mTOR in the cerebral cortex after epilepsy (Figures 4 and 5). The optical density of the band was used to further analyze the relative expression of the protein (Figure 4B). It was shown that protein and mRNA levels of of PI3K, Akt, and mTOR increased significantly in the KA group after epilepsy, and these increases were significantly attenuated by Everolimus treatment $(\mathrm{p}<0.05)$ (Fig. 4B and 5). Further comparison revealed that the protein and mRNA levels of mTOR, and the protein level of Akt in the $\mathrm{KA}+2 \mathrm{mg} / \mathrm{kg}$ Eve group was significantly lower than that in the KA+1mg/kg Eve and KA+5mg/kg Eve groups $(\mathrm{p}<0.05)$.

Western Blot and qRT-PCR results thus indicate that Everolimus can inhibit KA-induced activation of the PI3K/Akt signaling pathway after epilepsy in developing rats.

A

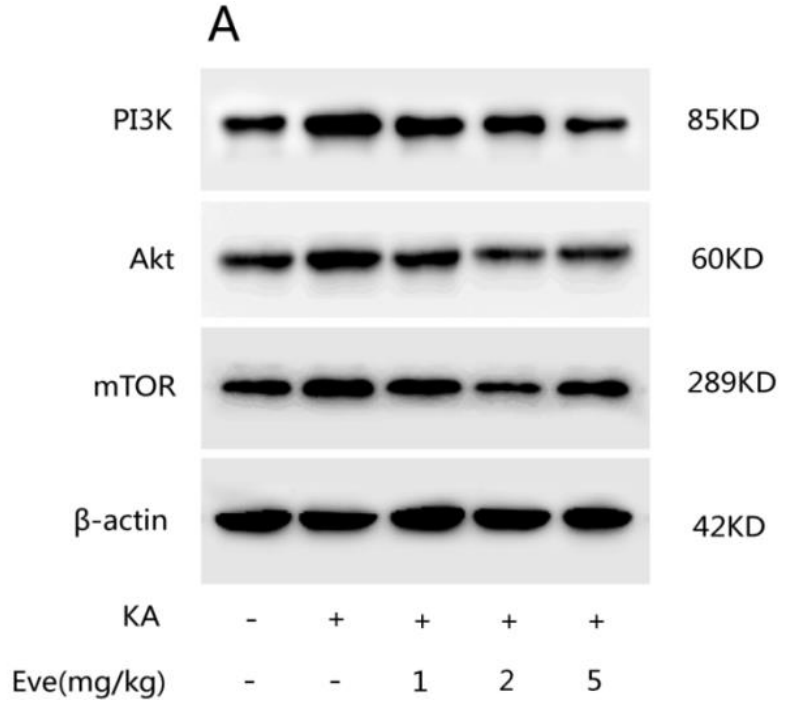

B

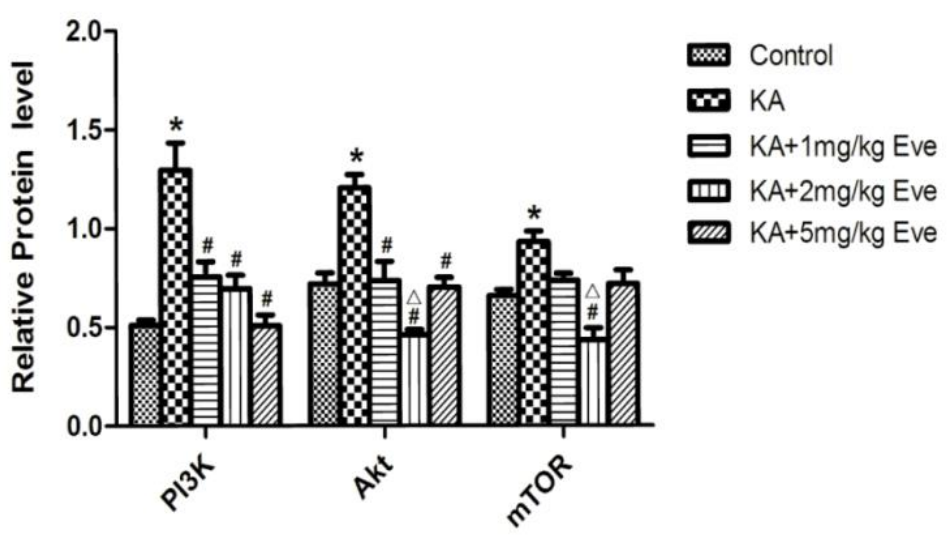

Fig.4 Everolimus reduces protein levels of PI3K, Akt and mTOR in the cerebral cortex. KA $15 \mathrm{mg} / \mathrm{kg}$ induced developmental rat epilepsy, and Everolimus was injected intraperitoneally 2 hours before KA injection. Protein levels of PI3K, Akt and mTOR were measured 24 hours after KA injection. A. Protein bands following Western Blot analysis. B. Relative protein levels (optical density). Measurement data were expressed as mean $\pm \mathrm{SD}(\mathrm{n}=20) . * \mathrm{P}<0.05$, KA group vs. control group; \# $\mathrm{P}<0.05$, Everolimus treated group $(1,2,5 \mathrm{mg} / \mathrm{kg}) \mathrm{vs.} \mathrm{KA}$ group; ${ }_{\triangle} \mathrm{P}<0.05, \mathrm{KA}+2 \mathrm{mg} / \mathrm{kg}$ Eve group vs. $\mathrm{KA}+1 \mathrm{mg} / \mathrm{kg}$ Eve group and $\mathrm{KA}+5 \mathrm{mg} / \mathrm{kg}$ Eve groups. 


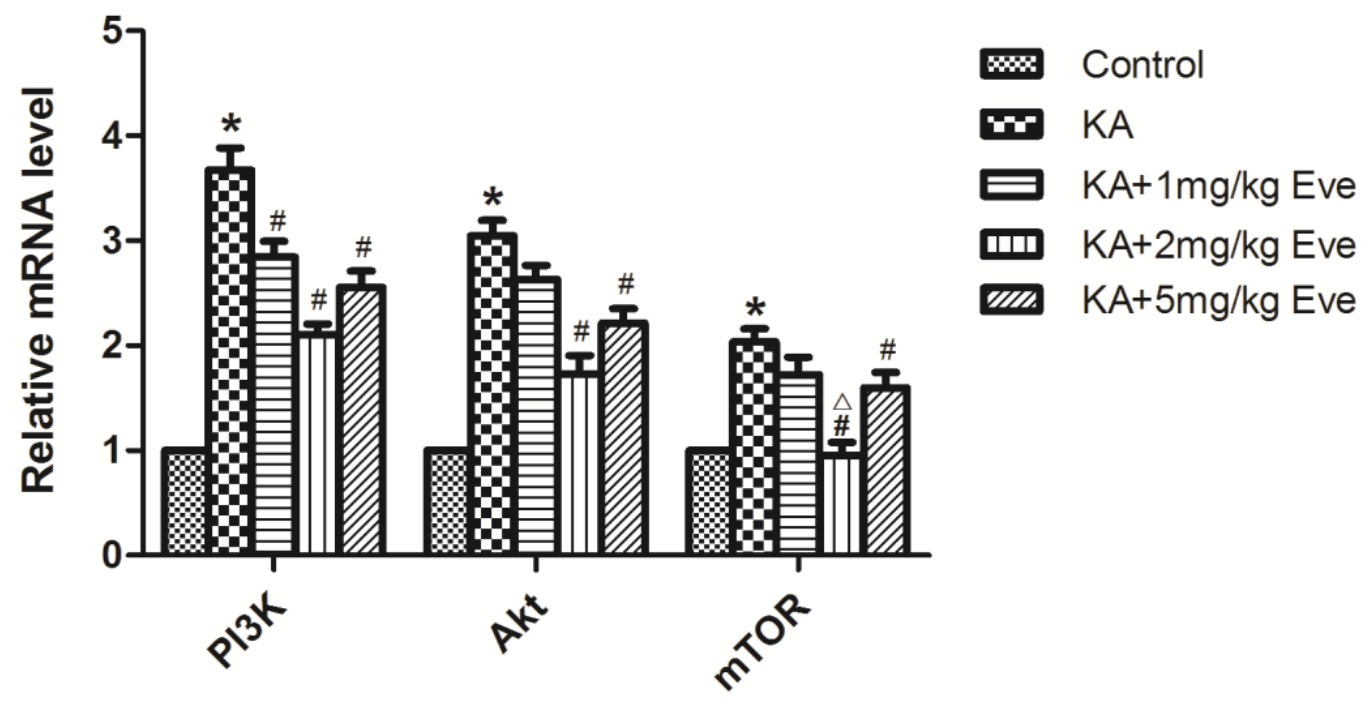

Fig. 5 Everolimus reduces mRNA levels of PI3K, Akt and mTOR in the cerebral cortex. Measurement data were expressed as mean $\pm \mathrm{SD}(\mathrm{n}=20)$. $* \mathrm{P}<0.05$, KA group vs. Control group; $\# \mathrm{P}<0.05$, Everolimus treated group $(1,2,5 \mathrm{mg} / \mathrm{kg})$ vs. KA group; $\triangle \mathrm{P}<0.05, \mathrm{KA}+2 \mathrm{mg} / \mathrm{kg}$ Eve group vs. KA+1 $\mathrm{mg} / \mathrm{kg}$ Eve group.

\subsection{Everolimus reduces the expression of NF-kB and IL-6}

To further investigate the effect of Everolimus on the NF-kB/IL-6 inflammatory signaling pathway, Western Blot and qRT-PCR were used to detect the protein and mRNA levels of NF-kB and IL-6 in the cerebral cortex after epilepsy (Figures 6 and 7). The results showed that protein and mRNA levels of NF-kB and IL-6 increased significantly in the KA group after induction of epilepsy, and these increases were inhibited by Everolimus treatment $(\mathrm{p}<0.05)$ (Fig. 6B and 7). Further comparison revealed that the protein and mRNA levels of NF-kB, and the mRNA level of IL-6 in the $\mathrm{KA}+2 \mathrm{mg} / \mathrm{kg}$ Eve group was significantly lower than that in the $\mathrm{KA}+5 \mathrm{mg} / \mathrm{kg}$ Eve group $(\mathrm{p}<0.05)$.

This result suggests that the NF-kB/IL-6 inflammatory signaling pathway is activated after epilepsy, and Everolimus can inhibit this KA-induced response. Furthermore the inhibitory effect is dose-dependent in this experiment, with $2 \mathrm{mg} / \mathrm{kg}$ Everolimus having the strongest inhibitory effect. 
A

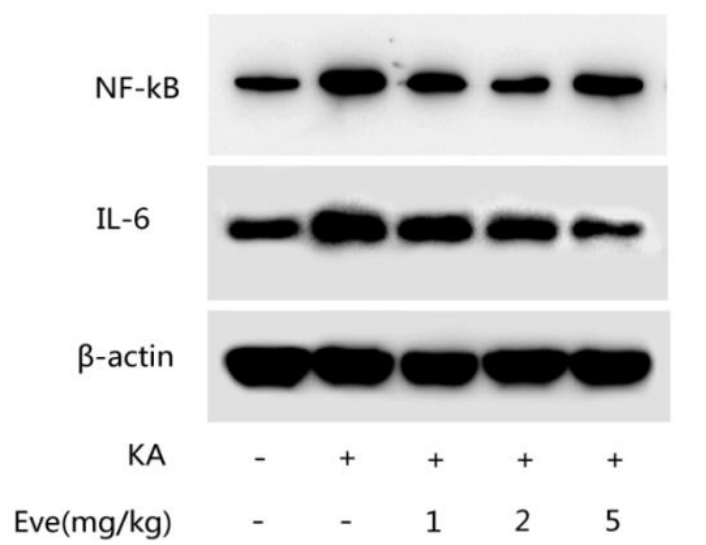

B

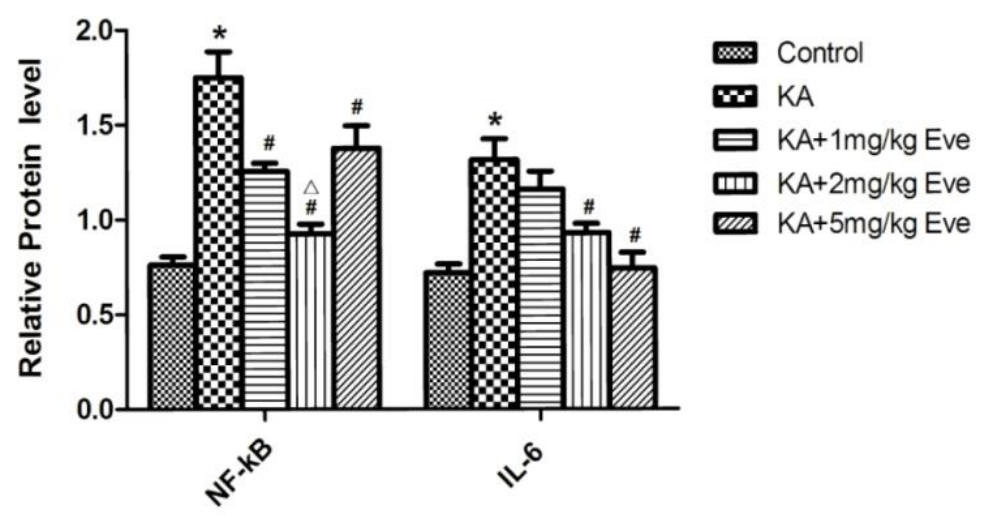

Fig.6 Everolimus reduces protein levels of NF-kB and IL-6 in the cerebral cortex. KA $15 \mathrm{mg} / \mathrm{kg}$ induced developmental rat epilepsy, and Everolimus was injected intraperitoneally 2 hours before KA injection. Protein levels of NF-kB and IL-6 were measured 24 hours after KA injection. A. Protein bands following Western Blot analysis. B. Relative protein levels (optical density). Measurement data were expressed as mean $\pm \mathrm{SD}(\mathrm{n}=20)$. $* \mathrm{P}<0.05$, KA group vs. control group; $\# \mathrm{P}<0.05$, Everolimus treated group $(1,2,5 \mathrm{mg} / \mathrm{kg}$ ) vs. KA group; $\triangle \mathrm{P}<0.05$, $\mathrm{KA}+2 \mathrm{mg} / \mathrm{kg}$ Eve group vs. $\mathrm{KA}+5 \mathrm{mg} / \mathrm{kg}$ Eve group.

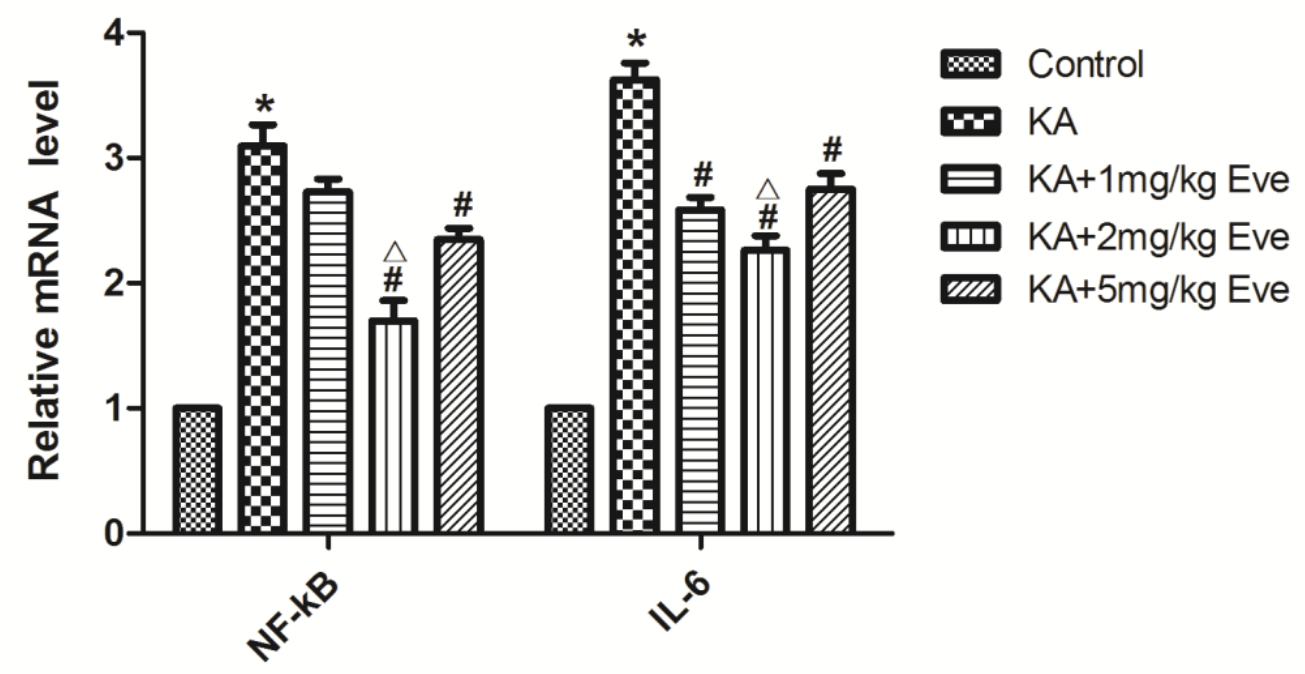

Fig.7 Everolimus reduces mRNA levels of NF-kB and IL-6 in the cerebral cortex. Measurement data were expressed as mean $\pm \mathrm{SD}(\mathrm{n}=20)$. $* \mathrm{P}<0.05$, KA group vs. Control group; ${ }_{\# \mathrm{P}<0.05}$, Everolimus treated group $(1,2,5 \mathrm{mg} / \mathrm{kg})$ vs. KA group; $\triangle \mathrm{P}<0.05, \mathrm{KA}+2 \mathrm{mg} / \mathrm{kg}$ Eve group vs. $\mathrm{KA}+5 \mathrm{mg} / \mathrm{kg}$ Eve group.

\section{Discussion}

Epilepsy is a highly prevalent neurological disease affecting approximately 50 million people worldwide. The disease is characterized by recurrent seizures that are caused by synchronous abnormal discharge of brain neurons [12]. Due to the inherent 
complexity of the central nervous system, research on the pathogenesis of convulsive brain injury is still very limited. Studies have shown that the pathological features of epilepsy include the proliferation of microglia, neuronal apoptosis, and an imbalance between inhibitory and excitatory neurotransmitters [13]. Most current antiepileptic drugs suppress neuronal excitability by regulating neurotransmitter receptors or ion and voltage-gated channels. These are in fact anticonvulsant medications rather than antiepileptic treatments, as they do not target the implicit underlying etiology [14]. In this experiment, we chose the kainic acid induced epilepsy model as it bears resemblance to human temporal lobe epilepsy, and is a stable, repeatable model.

Microglia are the main antigen presenting cells in the central nervous system and play an important role in maintaining the stability of the microenvironment of nerve cells [15]. Under normal circumstances, microglia are in a stationary state and can be activated upon abnormal stimulation, rapidly proliferating and migrating to the injured site, mediating neuroinflammation and inducing neuronal apoptosis [16]. Abraham et al. found that in KA-induced epilepsy rats, the number of microglia tripled in the brain and increased the susceptibility to epilepsy [17]. Therefore inhibiting the activation and subsequent proliferation of microglia may be an effective measure to reduce post-epileptic brain damage. In this experiment, we used the KA-induced rat epilepsy model. The results of immunohistochemistry showed that the number of activated microglia in the KA group was significantly higher than that in the Control group, confirming the involvement of microglia activation in the pathological progression of epilepsy. The specific mechanism suggests that activated microglia secrete a variety of immune effect molecules including interleukins IL-1, IL-6, IL-8, tumor necrosis factor and oxygen free radicals, which damage neurons, glial cells and the blood brain barrier. Inflammatory factors further aggravate the microenvironment, inducing seizures and causing post-epileptic brain damage $[18,19]$.

Phosphatidylinositide 3-kinases (PI3K) is an intracellular phosphatidylinositol kinase. It is a complex of multiple growth factors and signaling, including fibroblast growth factor (FGF), vascular endothelial growth factor (VEGF) and human growth factor (HGF) [20]. Serine/threonine kinase (Akt) is a specific protein kinase mainly expressed in the brain and testis. Akt is the downstream target of PI3K and can regulate apoptosis, protein synthesis, metabolism and the cell cycle through phosphorylated substrates [21]. Previous studies have shown that Akt can regulate a variety of proteins related to nerve function, including GABA receptors, ataxin-1 and huntingtin proteins. Akt can also regulate NF-kB/IL-6 signal transduction by phosphorylating IKK $\alpha$ and Tp12[22]. mTOR is a member of the PI3K-related kinase family and a downstream factor of PI3K/Akt signaling. The PI3K/Akt/mTOR signaling pathway plays an important role in cell growth by inhibiting apoptosis, including protein synthesis, tumor growth, and angiogenesis [23]. Western Blot and qPCR measured the protein and mRNA levels of PI3K/Akt/mTOR signaling pathway in the cerebral cortex of developing rats after epilepsy. The results indicated that the expression of PI3K, Akt, mTOR were significantly higher than that of the Control group, suggesting that PI3K/Akt signaling pathway is involved in the epilepsy pathological process. The reasons are considered as follows: 1)Excessive activation 
of mTOR can lead to gene expression of cerebral cortical malformation and the epileptic phenotype [24]; (2)PI3K/Akt/mTOR signaling pathway participates in cell synthesis and proliferation and promotes the synthesis of microglia[25], thereby aggravating the immune inflammatory response and increasing inflammatory cell exudation.(3)PI3K/Akt/mTOR signal activates hypoxia-inducible factors and regulates the glucose transporter (GLUT), resulting in excessive activation of neurons [26]. Contrary to the postulated role of the PI3K/Akt/mTOR pathway in epilepsy pathology, there have been reports that this signaling cascade confers protective effects due to reducing neuronal apoptosis and ischemic brain injury [27]. A reason for this may be that mTOR is part of two main signaling complexes, mTOR complex 1 (mTORC1) and mTOR complex 2 (mTORC2). mTORC1 regulates cell growth and metabolism, as well as other physiological functions, and mTORC2 regulates cell survival, metabolism and structure through the modulation of other downstream protein kinases and cytoskeletal elements[28]. Therefore we speculate that different pathway complexes may have different effects on epilepsy.

$\mathrm{NF}-\mathrm{kB}$ is an important nuclear transcription factor in the cytoplasm. Activated NF-kB can enter the nucleus and either initiate or inhibit the transcription of related genes[29]. Inflammatory cytokine IL-6 plays an important role in the inflammatory, immune and stress response, which is regulated by $\mathrm{NF}-\mathrm{kB}$ [30]. The results of Western Blot and qRT-PCR showed that the protein and mRNA levels of NF-kB and IL-6 significantly increased in the cerebral cortex after epilepsy, indicating that the NF-kB/ IL-6 signaling pathway is involved in the pathological process of epilepsy. The main pathological mechanism may be that microglia are activated during epileptic seizures, activating the NF-kB inflammatory signaling pathway and resulting in significantly increased levels of inflammatory cytokines such as IL- 6 , IL- $1 \beta$ and TNF- $\alpha$, leading to neuroinflammation[31]. NF-kB can furthermore activate microglia to release proinflammatory cytokines, increase neuron excitability and induce epilepsy [32].

Everolimus is a specific inhibitor of mTOR protein. In previous studies, Everolimus indirectly affected neuronal excitability by modulating specific ion channels such as potassium channels or proteins [33]. Currently, clinical use of Everolimus is primarily for anti-rejection of organ transplantation, autoimmune diseases and anti-tumor treatment [34-36]. Research on epilepsy is still very limited. In this experiment, it was observed that pre-treatment with Everolimus in KA-induced epileptic rats inhibited microglia activation, as well as the PI3K/Akt/mTOR and NF-kB/IL-6 signaling pathways. These inhibitory effects indicate that Everolimus may specifically target and reduce the pathological process of epilepsy, thus playing a protective role in brain damage post-epilepsy. Furthermore, experimental results indicate that Everolimus had the highest therapeutic efficacy at a dose of $2 \mathrm{mg} / \mathrm{kg}$, suggesting that the protective effect of Everolimus may be dose-dependent; the most suitable dose and time point of Everolimus administration require further research.

\section{Conclusions}

In conclusion, Everolimus can inhibit the proliferation and activation of microglia by regulating the PI3K/AKt/mTOR signaling pathway, and reduce the expression of 
inflammatory factors by inhibiting the NF-kB signaling pathway. These results indicate that Everolimus treatment may serve as a new strategy for protecting against epilepsy and other neurodegenerative diseases.

\section{Abbreviations}

Eve: Everolimus; KA: kanic acid; mTOR: mammalian target of repamycin; qRT-PCR: Reverse transcription-quantitative polymerase chain reaction;

ANOVA: one-way analysis of variance; PI3K: Phosphatidylinositide 3-kinases; Akt: Serine/threonine kinase; FGF: fibroblast growth factor; VEGF: vascular endothelial growth factor; HGF: human growth factor; mTORC1: mTOR complex 1; mTORC2: mTOR complex 2; GLUT: glucose transporter.

\section{Funding}

This project is supported by the Natural Science Foundation of Hunan Province

(Fund Number: 2019JJ40263), Outstanding Youth Project of Hunan Provincial Department of Education (Fund Number: 17B233) and Key project of Hunan Provincial Health Commission (Fund Number: 20200549), China.

\section{Conflicts of interest}

None of the authors has any conflict of interest to declare.

\section{Consent for publication}

All authors agree to publish the article.

\section{Ethics statement}

All animal breeding, care, feeding, and surgical procedures were approved by the Laboratory Animal Users Committee at the University of South China.

\section{List of author contributions}

QPH participated in the experiment design, performed experiments, wrote the first draft of the manuscript.

$\mathrm{XYH}$ participated in the experiment design, data collection, statistical analysis, data collation and proofing.

YYZ, RRH performed experiments and gathered data.

\section{Acknowledgements}

We are grateful to pediatric expert Wei Feng for their technical support. Experimental devices were provided by the Second Hospital, University of South China.

\section{Availability of data and materials}

The raw/processed data is currently not available for sharing as the data also forms part of an ongoing study. 


\section{References}

1. Aliasgharpour M, Dehgahn Nayeri N, Yadegary MA, et al. Effects of an educational program on self-management in patients with epilepsy[J]. Seizure, 2013,22: 48-52.

2. Kwan P, Brodie MJ. Refractory epilepsy: mechanisms and solutions[J]. Expert Rev Neurother, 2006,6(3):397-406.

3. Du L, Li X, Zhen L, et al. Everolimus inhibits breast cancer cell growth through PI3K/AKT/mTOR signaling pathway. Mol Med Rep. 2018;17(5):7163-7169.

4. Takei N, Nawa H. mTOR signaling and its roles in normal and abnormal brain development[J]. Front Mol Neurosci, 2014,7:28.

5. Cowan M, Petri WA Jr. Microglia: Immune Regulators of Neurodevelopment. Front Immunol. 2018;9:2576.

6. Coulter DA, Steinhäuser C. Role of astrocytes in epilepsy[J]. Cold Spring Harb Perspect Med, 2015,5(3).

7. Wong M, Crino PB. Tuberous sclerosis and epilepsy: role of astrocytes[J].Glia, 2012, 60(8):1244-1250.

8. Ostendorf A, Wong M. mTOR inhibition in epilepsy: rationale and clinical perspectives[J]. CNS Drugs,2015,29:91-99.

9. Gedaly R, De Stefano F, Turcios L, et al. mTOR Inhibitor Everolimus in Regulatory T Cell Expansion for Clinical Application in Transplantation. Transplantation. 2019;103(4):705-715.

10. Stefanidou M, Das RR, Beiser AS, et al. Incidence of seizures following initial ischemic stroke in a community-based cohort[J].Seizure, 2017,47: 105-110.

11. Fu H, Cheng Y, Luo H, et al. Silencing MicroRNA-155 Attenuates Kainic Acid-Induced Seizure by Inhibiting Microglia Activation. Neuroimmunomodulation. 2019;26(2):67-76.

12. Aronica E, Mühlebner A. Neuropathology of epilepsy. Handb Clin Neurol. 2017;145:193-216.

13. Shapiro LA, Wang L, Ribak CE. Rapid astrocyte and microglial activation following pilocarpine-induced seizures in rats[J]. Epilepsia,2008,49:33-41.

14. Rogawski MA, Löscher W, Rho JM. Mechanisms of Action of Antiseizure Drugs and the Ketogenic Diet. Cold Spring Harb Perspect Med. 2016;6(5):a022780.

15. Colonna M, Butovsky O. Microglia function in the central nervous system during health and neurodegeneration[J]. Annu Rev Immunol, 2017,35:441-468.

16. Brifault C, Gilder AS, Laudati E, et al. Shedding of membrane-associated LDL receptor-related protein-1 from microglia amplifies and sustains neuroinflammation[J]. J Biol Chem, 2017,292(45):18699-18712.

17. Abraham J, Fox PD, Condello C, et al. Minocycline attenuates microglia activation and blocks the long-term epileptogenic effects of early-life seizures[J]. Neurobiol Disease, 2012,46:425-430.

18. Trovão N, Prata J, VonDoellinger O, Santos S, Barbosa M, Coelho R. Peripheral Biomarkers for First-Episode Psychosis-Opportunities from the Neuroinflammatory Hypothesis of Schizophrenia. Psychiatry Investig. 2019;16(3):177-184.

19. Haruwaka K, Ikegami A, Tachibana Y, et al. Dual microglia effects on blood brain barrier permeability induced by systemic inflammation. Nat Commun. 2019;10(1):5816.

20. Rennel E, Mellberg S, Dimberg A, et al. Endocan is a VEGF-A and PI3K regulated gene 
with increased expression in human renal cancer. Exp Cell Res. 2007;313(7):1285-1294.

21. Ediriweera MK, Tennekoon KH, Samarakoon SR. Role of the PI3K/AKT/mTOR signaling pathway in ovarian cancer: Biological and therapeutic significance[J]. Semin Cancer Biol, 2019,59:147-160.

22. Luo LH, Li DM, Wang YL, et al. Tim3/galectin-9 alleviates the inflammation of TAO patients via suppressing Akt/NF-kB signaling pathway[J]. Biochem Biophys Res Commun, 2017,491(4):966-972.

23. Guerrero-Zotano A, Mayer IA, Arteaga CL. PI3K/AKT/mTOR: role in breast cancer progression, drug resistance, and treatment[J]. Cancer Metastasis Rev,2016, 35:1-10.

24. Yang GS, Zhou XY, An XF, et al. mTOR is involved in stroke-induced seizures and the anti-seizure effect of mild hypothermia[J]. Mol Med Rep. 2018;17(4):5821-5829.

25. Du M, Sun Z, Lu Y, Li YZ, Xu HR, Zeng CQ. Osthole inhibits proliferation and induces apoptosis in BV-2 microglia cells in kainic acid-induced epilepsy via modulating PI3K/AKt/mTOR signalling way. Pharm Biol. 2019;57(1):238-244.

26. Inglis DJ, Lavranos TC, Beaumont DM, et al. The vascular disrupting agent BNC105 potentiates the efficacy of VEGF and mTOR inhibitors in renal and breast cancer[J]. Cancer Biol Ther, 2014,15: 1552-1560.

27. Pang Y, Zhu S, Pei H. Pachymic acid protects against cerebral ischemia/reperfusion injury by the PI3K/Akt signaling pathway[J]. Metab Brain Dis, 2020,10.

28. Wong M. A critical review of mTOR inhibitors and epilepsy: from basic science to clinical trials. Expert Rev Neurother. 2013;13(6):657-669.

29. Mitchell S, Vargas J, Hoffmann A. Signaling via the NFאB system. Wiley Interdiscip Rev Syst Biol Med. 2016;8(3):227-241.

30. Zhang $\mathrm{M}$, Wang $\mathrm{C}$, Wu $\mathrm{J}$, et al. The Effect and Mechanism of KLF7 in the TLR4/NF-אB/IL-6 Inflammatory Signal Pathway of Adipocytes. Mediators Inflamm. 2018;2018:1756494.

31. Hongyan L, Mengjiao Z, Chunyan W, Yaruo H. Rhynchophyllin attenuates neuroinflammation in Tourette syndrome rats via JAK2/STAT3 and NF-kB pathways. Environ Toxicol. 2019;34(10):1114-1120.

32. Kovács Z, Czurkó A, Kékesi KA, et al. Intracerebroventricularly administered lipopolysaccharide enhances spike-wave discharges in freely moving WAG/Rij rats[J]. Brain Res Bull,2011,85(6):410-416.

33. Helgeland E, Breivik L, Sishi BJ, et al. Intermittent insulin treatment mimics ischemic postconditioning via MitoKATP channels, ROS, and RISK[J]. Scand Cardiovasc J, 2015, 49(5):270-279.

34. Pascual J, Berger SP, Witzke O, et al. Everolimus with Reduced Calcineurin Inhibitor Exposure in Renal Transplantation. J Am Soc Nephrol. 2018;29(7):1979-1991.

35. Han R, Gao J, Zhai H, Xiao J, Ding Y, Hao J. RAD001 (everolimus) attenuates experimental autoimmune neuritis by inhibiting the mTOR pathway, elevating Akt activity and polarizing M2 macrophages. Exp Neurol. 2016;280:106-114.

36. Lee L, Ito T, Jensen RT. Everolimus in the treatment of neuroendocrine tumors: efficacy, side-effects, resistance, and factors affecting its place in the treatment sequence. Expert Opin Pharmacother. 2018;19(8):909-928. 


\section{Figures}

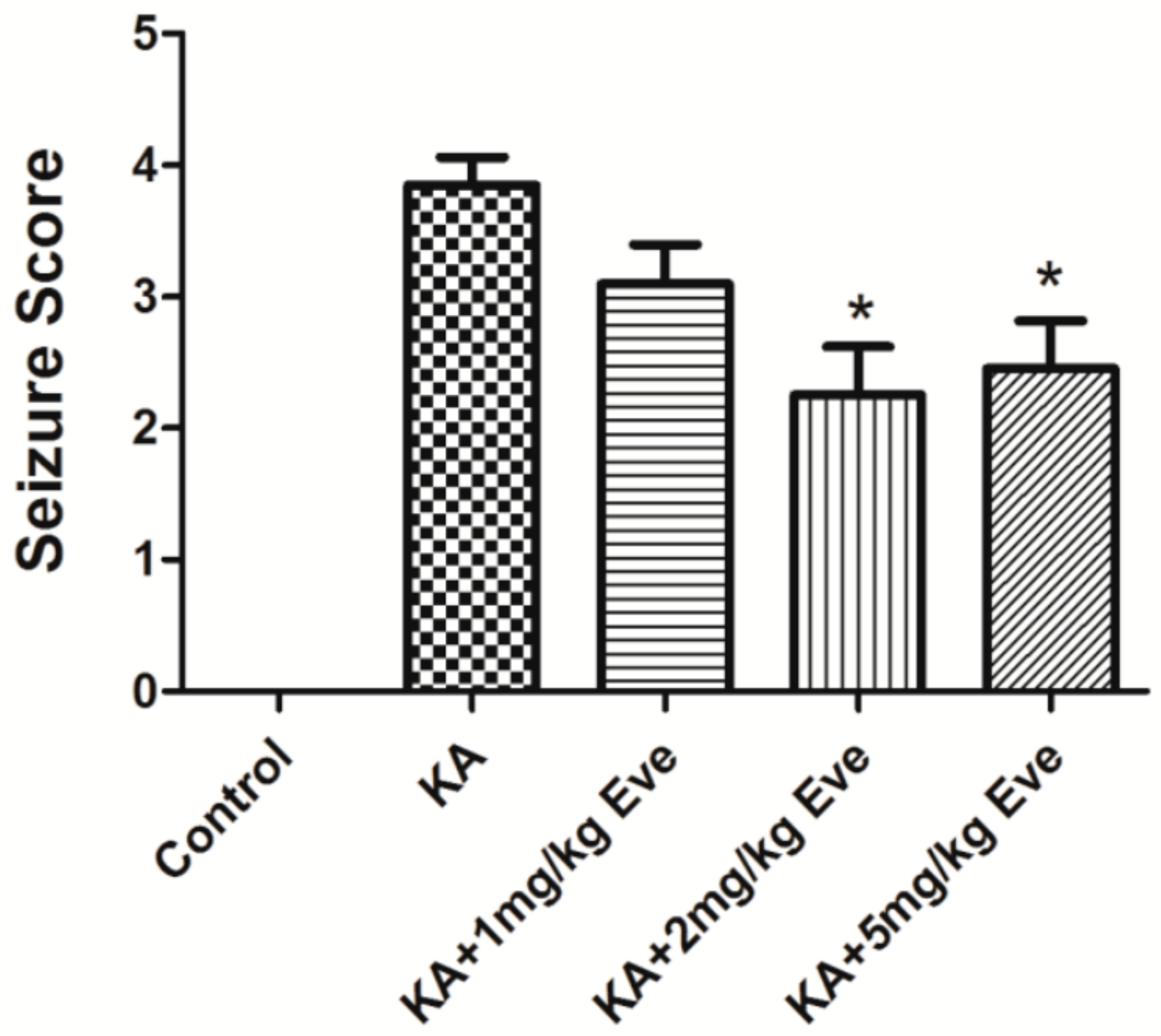

Figure 1

Everolimus reduces seizure grade scores. $\mathrm{KA} 15 \mathrm{mg} / \mathrm{kg}$ induced developmental rat epilepsy, and different doses of Everolimus (1, 2, $5 \mathrm{mg} / \mathrm{kg}$ ) were injected intraperitoneally 2 hours before KA injection. Seizure stage was assessed during 0.5-1 hours after KA injection. Measurement data were expressed as mean $\pm S D(n=20) .{ }^{*}<0.05$, compared with KA group. 


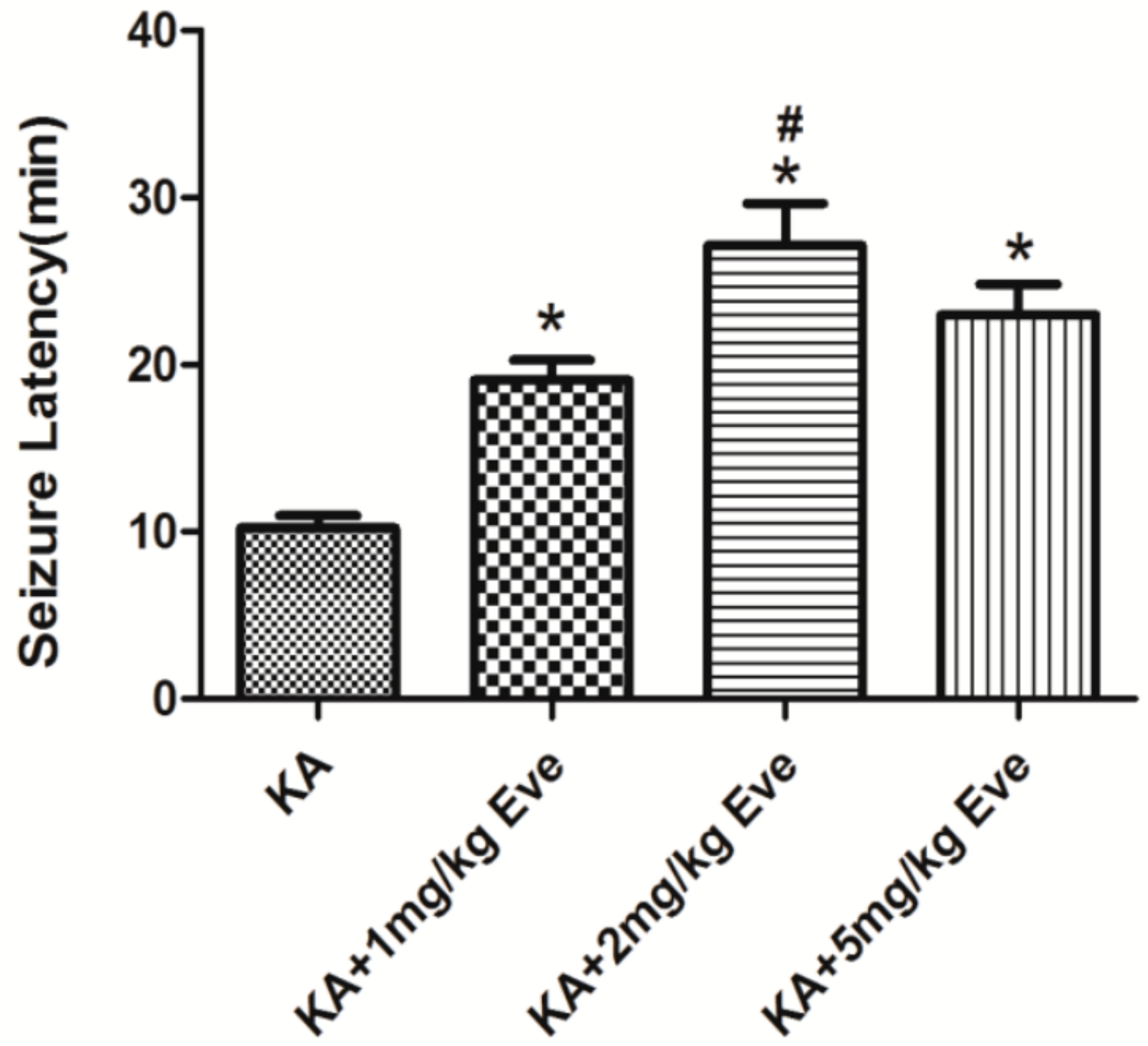

Figure 2

Everolimus increases seizure latency. KA $15 \mathrm{mg} / \mathrm{kg}$ induced developmental rat epilepsy, and different doses of Everolimus (1, 2, $5 \mathrm{mg} / \mathrm{kg}$ ) were injected intraperitoneally 2 hours before KA injection. Seizure latency was assessed. Measurement data were expressed as mean $\pm S D(n=20)$. ${ }^{*}<0.05$, compared with KA group; \#P<0.05, compared with $\mathrm{KA}+1 \mathrm{mg} / \mathrm{kg}$ Eve group. 

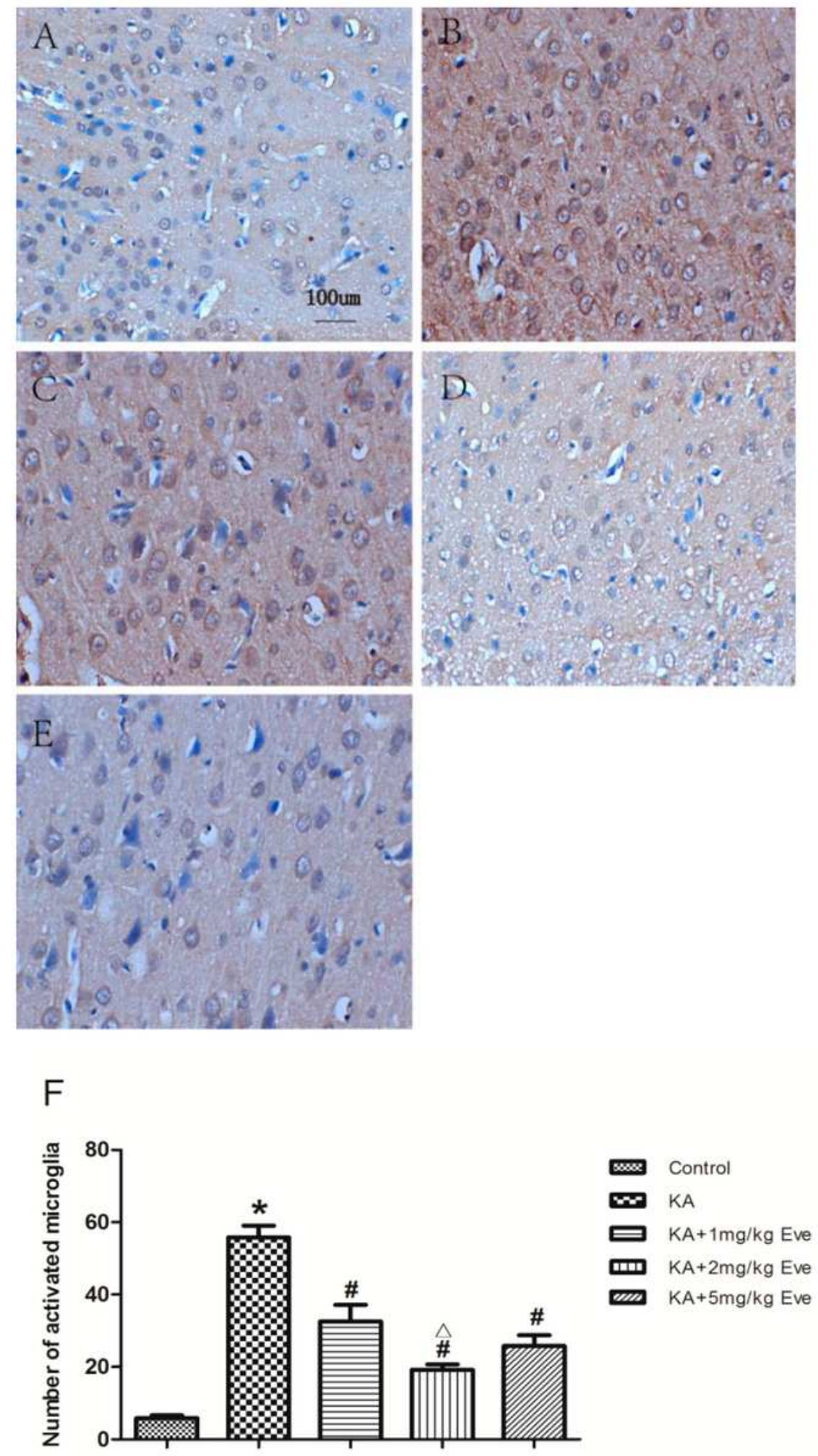

\section{Figure 3}

Everolimus reduces microglia activation in the cerebral cortex. $\mathrm{KA} 15 \mathrm{mg} / \mathrm{kg}$ induced developmental rat epilepsy, and Everolimus (1, 2, $5 \mathrm{mg} / \mathrm{kg}$ ) was injected intraperitoneally 2 hours before KA injection. Pathological sections of brain tissue were observed 24 hours after KA injection. A. Control group B. KA group C. KA+1 mg/kg Eve group D. KA+2mg/kg Eve group E. KA+5mg/kg Eve group. F. Iba1 positive cells quantities for each group. Measurement data were expressed as mean $\pm S D$. Scale bar $=100 \mu \mathrm{m} .{ }^{*} P<0.05$, 
$K A$ group vs. control group; $\# \mathrm{P}<0.05$, Everolimus treated group $(1,2,5 \mathrm{mg} / \mathrm{kg})$ vs. $\mathrm{KA}$ group; $\triangle \mathrm{P}<0.05$, $\mathrm{KA}+2 \mathrm{mg} / \mathrm{kg}$ Eve group vs. KA+1mg/kg Eve.

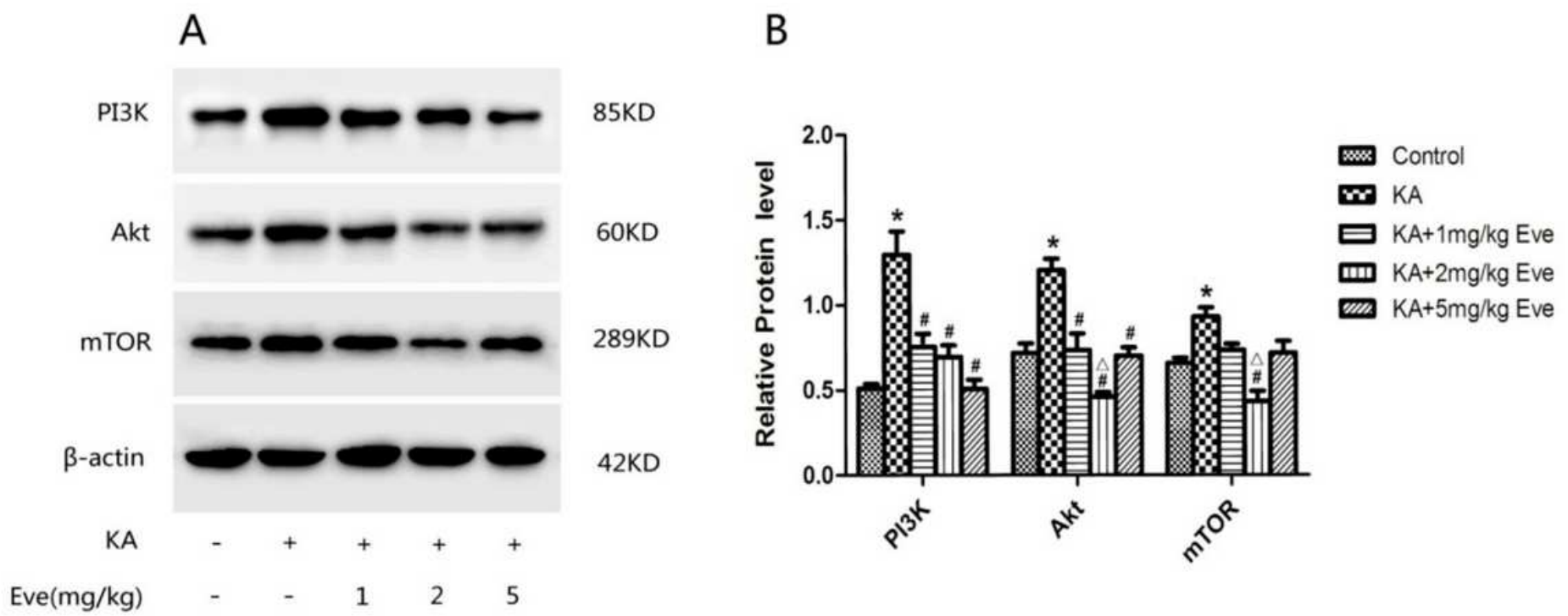

\section{Figure 4}

Everolimus reduces protein levels of PI3K, Akt and mTOR in the cerebral cortex. KA $15 \mathrm{mg} / \mathrm{kg}$ induced developmental rat epilepsy, and Everolimus was injected intraperitoneally 2 hours before KA injection. Protein levels of PI3K, Akt and mTOR were measured 24 hours after KA injection. A. Protein bands following Western Blot analysis. B. Relative protein levels (optical density). Measurement data were expressed as mean $\pm S D(n=20)$. ${ }^{*}<0.05, K A$ group vs. control group; $\# P<0.05$, Everolimus treated group $(1,2,5 \mathrm{mg} / \mathrm{kg})$ vs. KA group; $\otimes P<0.05, K A+2 \mathrm{mg} / \mathrm{kg}$ Eve group vs. $\mathrm{KA}+1 \mathrm{mg} / \mathrm{kg}$ Eve group and $\mathrm{KA}+5 \mathrm{mg} / \mathrm{kg}$ Eve groups. 


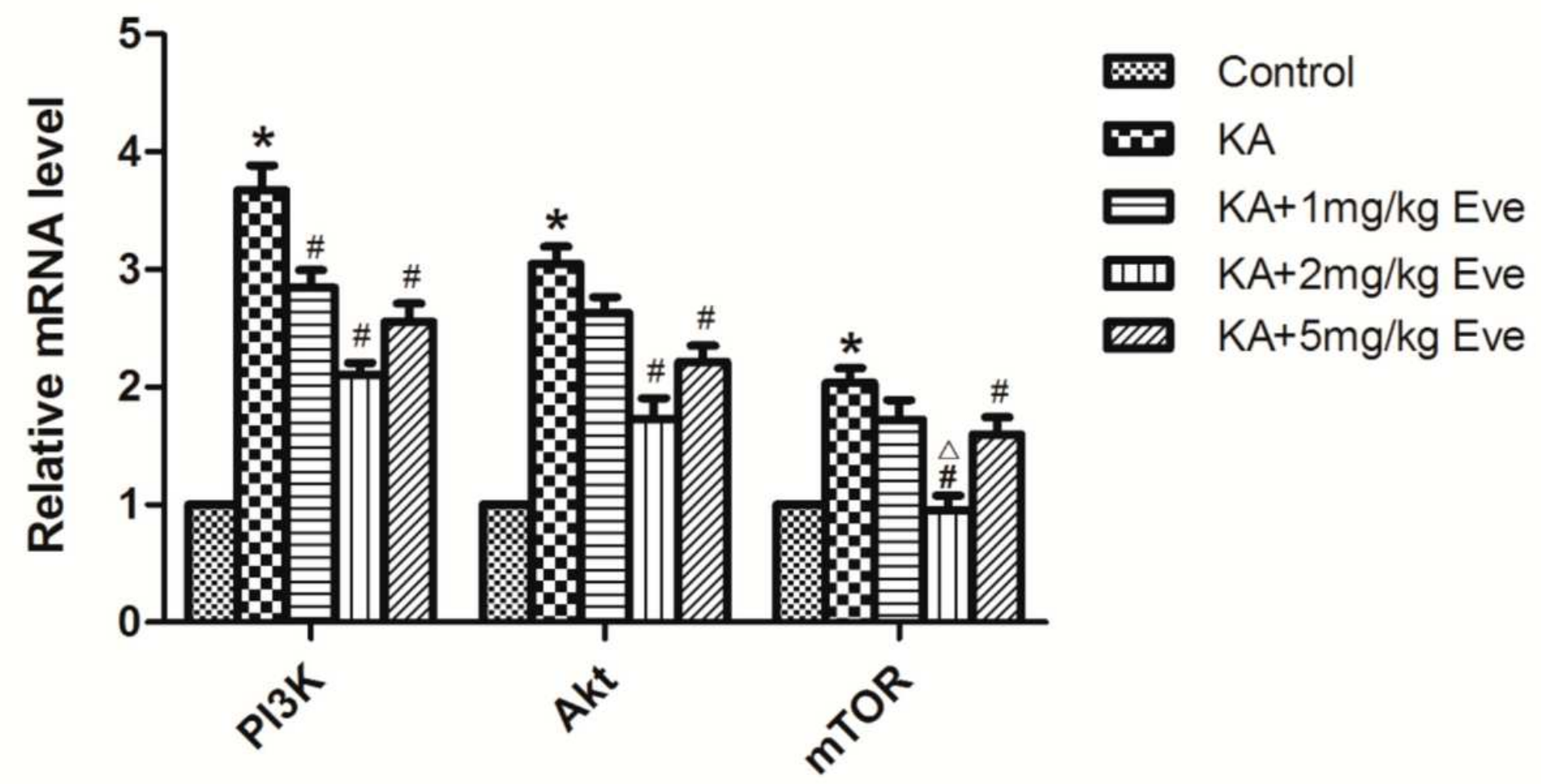

Figure 5

Everolimus reduces mRNA levels of $\mathrm{PI} 3 \mathrm{~K}, \mathrm{Akt}$ and $\mathrm{mTOR}$ in the cerebral cortex. Measurement data were expressed as mean $\pm S D(n=20)$. ${ }^{*}<<0.05, K A$ group vs. Control group; $\# P<0.05$, Everolimus treated group $(1,2,5 \mathrm{mg} / \mathrm{kg})$ vs. $\mathrm{KA}$ group; $\otimes \mathrm{P}<0.05, \mathrm{KA}+2 \mathrm{mg} / \mathrm{kg}$ Eve group vs. $\mathrm{KA}+1 \mathrm{mg} / \mathrm{kg}$ Eve group.

A

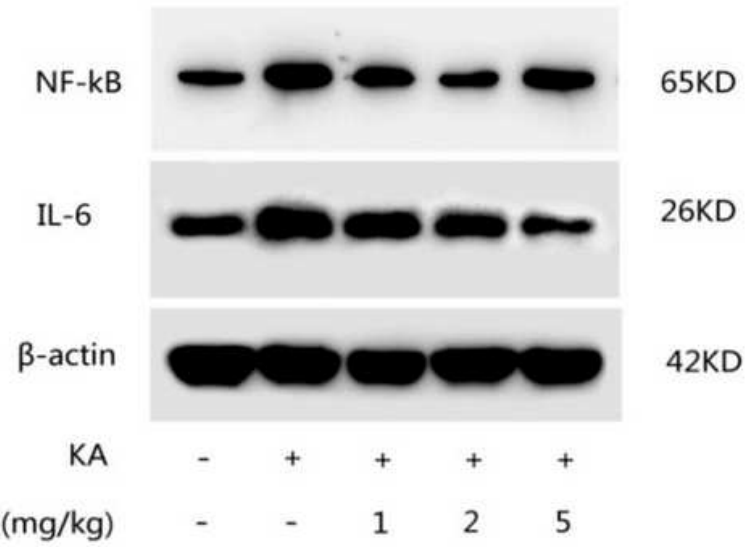

B

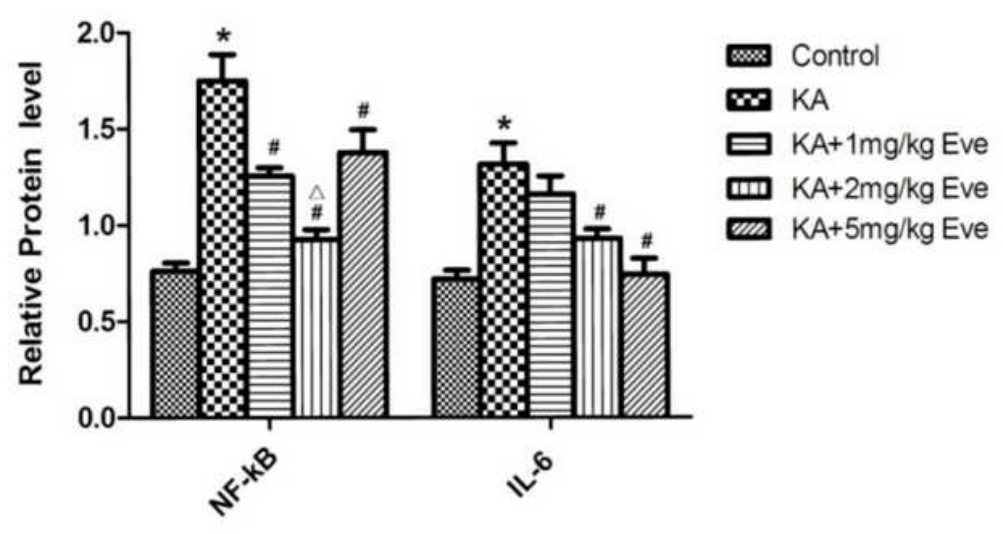

Figure 6

Everolimus reduces protein levels of NF-kB and IL- 6 in the cerebral cortex. KA $15 \mathrm{mg} / \mathrm{kg}$ induced developmental rat epilepsy, and Everolimus was injected intraperitoneally 2 hours before KA injection. Protein levels of NF-kB and IL-6 were measured 24 hours after KA injection. A. Protein bands following 
Western Blot analysis. B. Relative protein levels (optical density). Measurement data were expressed as mean $\pm S D(n=20)$. ${ }^{*}<0.05, K A$ group vs. control group; $\# P<0.05$, Everolimus treated group $(1,2,5 \mathrm{mg} / \mathrm{kg})$ vs. $K A$ group; $\otimes P<0.05, K A+2 m g / k g$ Eve group vs. $K A+5 m g / k g$ Eve group.

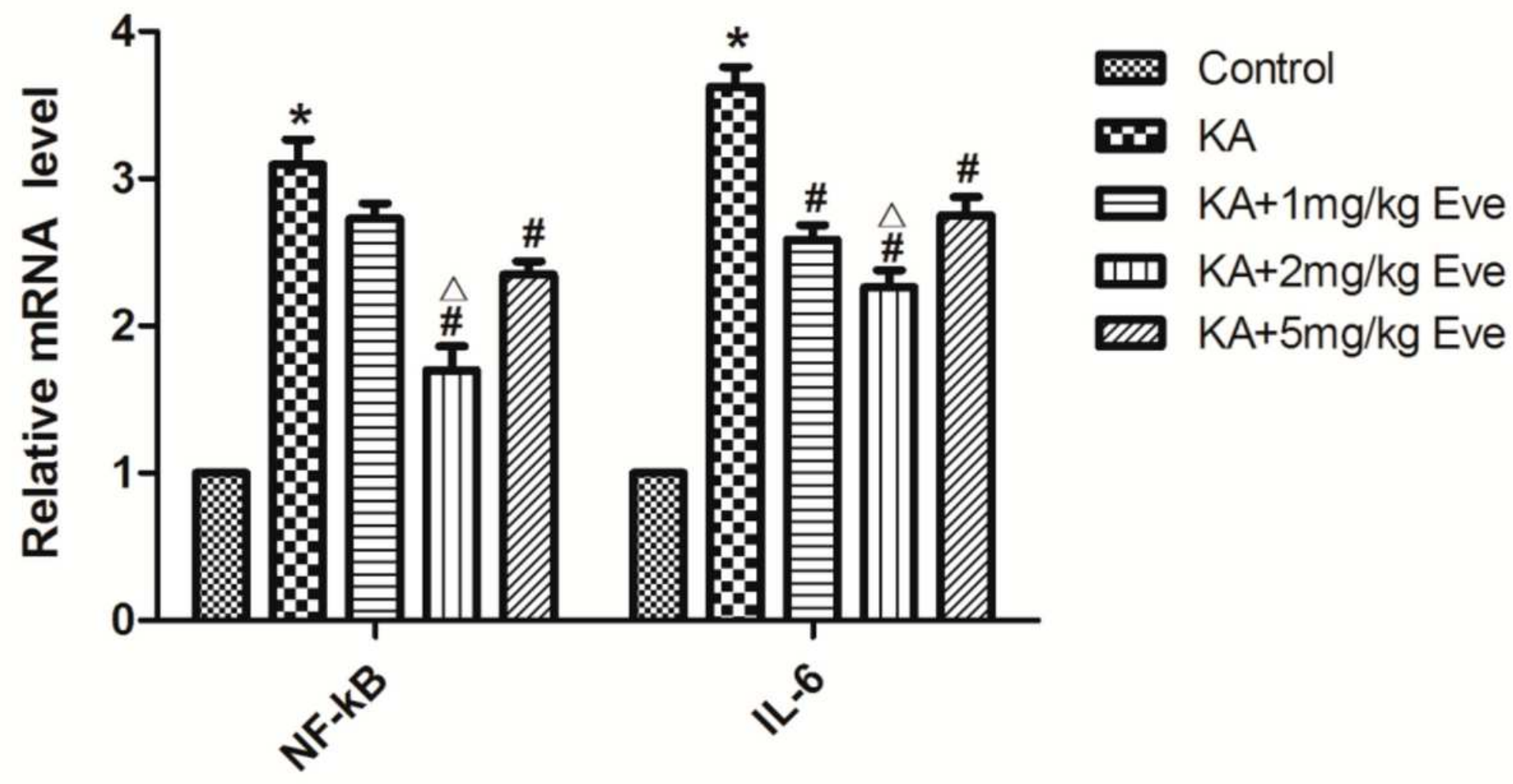

Figure 7

Everolimus reduces mRNA levels of NF-kB and IL-6 in the cerebral cortex. Measurement data were expressed as mean $\pm S D(n=20)$. ${ }^{*}<0.05, K A$ group vs. Control group; $\# P<0.05$, Everolimus treated group $(1,2,5 \mathrm{mg} / \mathrm{kg})$ vs. $\mathrm{KA}$ group; $\varangle \mathrm{P}<0.05, \mathrm{KA}+2 \mathrm{mg} / \mathrm{kg}$ Eve group vs. $\mathrm{KA}+5 \mathrm{mg} / \mathrm{kg}$ Eve group. 